\title{
Temporal Landmarks
}

\author{
Johanna Peetz \\ Mariya Davydenko \\ Carleton University
}

Peetz, J., \& Davydenko, M. (in press). Temporal landmarks. In F. Grouzet (Ed.), Oxford Handbook of Psychology of Time Travel and Temporality. Oxford, UK: Oxford University Press. 
Time is a dimension of all our actions and thoughts, yet we rarely consider how our mental representations of time might affect us. One of the most common forms of time representation is a calendar. Every day we might check and enter plans in a calendar or simply consider the events of next month, or next year, to orient ourselves in time. Now, picture a calendar. In this time representation, the days in a given month or year are not all alike. Some days stand out - national or religious holidays, personal events such as birthdays, or even weekends, might be highlighted. Such markings might reflect more generally how time is perceived. Rather than a continuous flow of time, some events and dates might stand out as temporal landmarks on the temporal horizon. When remembering, planning and contemplating our past and future lives, we use these temporal landmarks to orient ourselves in time. Someone might describe an event as having happened "after the New Year, but before my birthday." Someone might add temporal landmarks to their roadmap of long term future plans and goals (e.g., "after I graduate from college"; or "before the baby is born"). Thus, much as physical landmarks help our orientation in geographical space, temporal landmarks may structure our perception of time. Which temporal landmarks stand out - which dates we choose to highlight in our calendars - can have surprising consequences. In this chapter, we review how temporal landmarks may shape our thoughts about the past and future and might influence goal pursuit.

\section{Definition}

Any important point in time that stands out in the everyday humdrum of life may be a temporal landmark. These might be vivid public events that oneself may or may not be personally involved in (e.g., an election), significant personal events (e.g., life transitions, first experiences), culturally shared events (e.g., Christmas) or simply the first day of a month, first day of the year. Some temporal landmarks may recur with regularity (e.g., holidays and 
anniversaries) and others may be unique (e.g., a wedding). Some temporal landmarks may be positive (e.g., a birthday) others may be negative (e.g., 9/11 anniversary). In sum, any event or date that stands out as a salient feature on the temporal horizon may act as temporal landmark.

\section{Temporal landmarks in the past}

Time extends in two directions - the past and the future. Temporal landmarks may guide how we look backwards in time, as well as structure our perception of what lies ahead. Early work on temporal landmarks focused on how temporal landmarks might affect thoughts about the past. In a review that coined the term "temporal landmark", Shum (1998) reviewed evidence that public events, personal events, and calendar events can organize thoughts about the past specifically, our memories.

Memory. As features that stand out on the temporal horizon of the past, temporal landmarks can call attention to the "surrounding" events temporally close to the landmark. Memory for events around a temporal landmark can therefore be improved relative to other memories. For example, students' recall for events peaks around the beginning and end of the academic calendar (Kurbat, Shevell, \& Rips, 1998; Pillemer, Rhinehart, \& White, 1986; Robinson, 1986): they retrieved almost three times as many memories from the beginning of the academic year than of any other time (Pillemer, Rhinehart, \& White, 1986). Likewise, the reminiscence peak for memories in the second and third decade of life (e.g., Rubin, Wetzler, \& Nebes, 1985) might be explained by the density of first-time experiences (i.e., landmark experiences) during this time.

In addition to increase the amount of retrieved data, landmarks may also increase the accuracy of dating these events (e.g., Larsen, Thompson, \& Hansen, 1996; Thompson, Skowronski, Larsen, \& Betz, 1996; Zwartz \& Sharman, 2013). Dates can be reconstructed by 
situating a memory in the context of landmarks such as "it happened after I broke up with Tom, but before my birthday, so it must have been in August". Providing people with a temporal landmark, which position in time was known to them (e.g., "Did this occur during high school or college?", "Did this occur before or after the assassination of Kennedy?"), facilitated the dating of other events, as indicated by faster responses (Brown, Shevell, \& Rips, 1986), reduced tendency to telescope (i.e., date events more recent than they really are; Loftus \& Marburger, 1983; Zwartz \& Sharman, 2013) and generally improved dating accuracy (Zwartz \& Sharman, 2013).

Identity. In addition to calling attention to a specific point in time, temporal landmarks such as first-time experiences or personally important events can also mark a shift in identity. Important transition experiences (e.g., becoming a parent, finishing school) are not only more memorable than other days in one's life but also constitute the beginning of a new self or identity.

The self can be seen as collection of identities through time (Parfit, 1984; also see Wilson \& Williams, this handbook). Indeed, a distant past self or future self may be akin to a stranger in one's mind (Parfit, 1971; Ersner-Hershfield, Wimmer, \& Knutson, 2009). This increasing distance to past (or future) selves over a lifetime is not a continuous chain of increasingly different, estranged, selves, but is instead grouped in temporal categories. Indeed, when telling their life story older adults organize their life narrative into chapters (Skowronski et al., 2007; Thomsen, 2009; Thomsen \& Berntsen, 2008). Thus, people tend to organize or categorize their lives into distinct categories (e.g., "college years"), with temporal landmarks bracketing beginning and end of the category (e.g., "frosh week", "graduation"). A major life transition (i.e., the birth of a child) might usher in a new subjective stage in life, a new self (i.e., "being a 
parent"). Indeed, major transitions have been shown to be linked to self-concept change (Cantor et al., 1987; Kling, Ryff, \& Essex, 1997; Uzer \& Brown, 2015). For example, student's description of themselves changed significantly as they transitioned from high school to university (Cantor et al., 1987). Accordingly, temporal landmarks might not only affect memory of events but also change how we think about ourselves across time.

\section{Temporal landmarks in the future}

When looking ahead in time and planning or anticipating the future, temporal landmarks can stand out from the temporal landscape as well. We often know that certain events will happen in the future, regardless of whether they are unique (wedding, birth) or recurring (anniversaries, holidays). What might be the result of highlighting these events when people are contemplating their future self or future actions?

Identity. Just as temporal landmarks in the past can indicate the beginning of a new self, so might anticipated landmarks mark an anticipated shift in identity. A person may feel more disconnected from their future self if this self is perceived as falling after a psychologically important event. Anticipated life transitions (e.g., becoming a parent or getting divorced) may be such salient landmarks that they chronically bisect the temporal landscape of one's life, similar to past life transitions (Cantor et al., 1987; Kling et al., 1997; Uzer \& Brown, 2015). These events cause real life changes, so a sense of disconnection with selves on the other side of the landmark may be relatively unsurprising and based largely in fact. However, is the same true of temporal landmarks more generally? Temporal landmarks may not necessarily be personally important events that include change inherent in themselves. One can hardly become a parent without seeing change in aspects of one's identity; but one can surely pass another New Year's Day (or another birthday, another Mother's Day) without finding daily life (or the self) to be 
much different. However, even mundane landmarks that are routine and culturally shared, and by and large do not indicate meaningful change in any inherent way, may also act as temporal markers. In other words, when landmarks are made salient, they might temporarily organize time into different temporal categories, and consequently create a sense of "new beginnings" regardless of their relevance for genuine self-change.

Shifting Identity. If even mundane landmarks introduce a sense of the self "before" vs. "after" a specific event, the sense of self and anticipated self should change with it, even if the landmark does not inherently imply meaningful change (just another New Year's Day, rather than the birth of one's child). One way to examine whether this is the case, is to examine people's evaluation of the person they expect to be at a future point in time while making an intervening temporal landmark salient - or not. Indeed, when evaluating in November what they might be like in January, people saw this future self as more different from their current self if New Year's Day was made salient than if it was not (Peetz \& Wilson, 2012). Thus, highlighting a temporal landmark seemed to create temporal categories, dissecting the future into "then" vs. "now", with the future self seen as more different from the current self when falling into a different temporal category. The same occurred when other relatively mundane landmarks were called to mind before participants were asked to evaluate a future self after these landmarks: participants' own birthdays, their country's previous presidents' birthdays, mother's day, or Christmas Day (Peetz $\&$ Wilson, 2012). Thus, there is evidence suggesting that temporal landmarks can reduce connectedness between two temporal selves, regardless of actual change in the self and regardless of how distant that future self really is.

This shift in connection between selves seems to run two ways. If the current self is evaluated first, the future self may be seen in a way that exaggerates differences if an intervening 
landmark is made salient. However, if the future self is evaluated first, landmarks can shift the evaluation of the present self to appear more similar or more different. Specifically, participants rated themselves right now more positively after imagining a positive (rather than a negative) future self placed in the same temporal category - but rated themselves now more negatively if the positive future self was placed in a different temporal category (Peetz \& Wilson, 2012). Thus, calling attention to specific features in the temporal landscape can shift identity according to whether these temporal landmarks fall before or after an anticipated self. Relatively mundane events that are routine and culturally shared can act as a psychological barrier between two selves - and exaggerate differences between selves - if they intersect them temporally.

Manipulating Identity. It stands to reason that people prefer to be associated with positive selves and separated from negative selves (Wilson \& Ross, 2000; Ross \& Wilson, 2002). If temporal landmarks allow for such separation, people might spontaneously use them to place barriers between their current self and unfavorable future selves. Indeed, when given the choice to write about one of two national holidays, people chose to talk about the holiday that fell in between their current self and an unfavorable future self more often than a holiday that fell after the future self (Peetz \& Wilson, 2013) - therefore placing the unfavorable future self in a different temporal category. This preference for focusing on landmarks that fall between the present and a negative future self was also present when people could nominate the events themselves (calendar events such as Easter or Christmas or personal events such as birthdays or a friend's wedding): participants preferred thinking about those temporal landmarks that fell in between the present and a negative future self (Study 3, Peetz \& Wilson, 2013). Furthermore, this use of landmarks to set barriers between the current and a temporally extended self was effective: When given a chance to write about an intervening temporal landmark that fell before 
a negative future self, participants appraised their current self more positively than when writing about a different landmark (Peetz \& Wilson, 2015). Thus, people may use temporal landmarks strategically to ward against negative selves and psychologically distance themselves from such threats, while including positive selves in the same temporal category to associate closer with them.

Goal pursuit. Beyond regulating identity and managing the positivity of self-appraisal, there are other consequences to perceiving more or less connection between temporal selves. Connected temporal selves are more relevant to the current self than disconnected selves (Wilson \& Ross, 2001; Wilson \& Williams, this handbook), and in turn, connections between selves may impact how arduously future selves are pursued (or avoided). Thus, salient temporal landmarks that connect or disconnect the current self from a desired "goal" self may affect the motivation and the degree to which a goal is actually pursued.

There are two possible ways in which connection to a future self may affect goals. On the one hand, contrasting the current self with a desired future self may be motivating because it activates discrepancy-reduction processes (Hoyle \& Sherrill, 2006; Carver \& Scheier, 1998). Indeed, perceiving a contrast between the current state and the desired state motivates people to close this gap (Adriaanse, de Ridder, \& de Wit, 2009; Amir \& Ariely, 2008; Koo \& Fishbach, 2008; Oettingen, Mayer, \& Thorpe, 2010; Oettingen et al., 2009; Oettingen \& Gollwitzer, 2009). For example, when participants who were committed to a goal (supporting a charity) focused on the discrepancy between the current charity funds and the target charity funds, they pledged the most money to donate in support of the goal (Koo \& Fishbach, 2008). Thus, disconnecting the current from a desired future self by means of placing a temporal landmark as psychological 
barrier between them may highlight the discrepancy between actual and ideal states and thus motivate goal pursuit.

On the other hand, greater connection to the future self may make a future "goal" self appear more imminent and spur people to take steps towards achieving it. Connection to a future self has been linked to goal-oriented behaviors such as higher saving intentions and less discounting (Bartels \& Rips, 2010; Ersner-Hershfield, Wimmer, \& Knutson, 2009; Ungemach, Stewart, \& Reimers, 2011). Subjective closeness to an upcoming test has been shown to increase motivation to study and actual studying behavior (Peetz, Wilson, \& Strahan, 2009). Thus, connecting the current self to a desired future self by means of placing them in the same temporal category may also increase goal pursuit.

There is evidence of temporal landmarks resulting in both of these possible outcomes. First, temporal landmarks that place the future self in a different category than the present self can motivate people to adopt and pursue a goal. Peetz and Wilson (2012) showed that when thinking of a desired healthy self six weeks in the future, participants reported being more motivated to improve their health if reminded that Christmas Day would fall in between the current and that future self. Similarly, calendars that emphasized intervening landmarks (holidays, weekends) between now and a future desired healthy self increased the motivation to improve health and increased the likelihood that people would take first steps towards achieving their health goal, such as choosing healthier cookbooks, and picking up exercise brochures. Importantly, in these studies, temporal landmarks highlighted the gap between current state and desired future state - that is, participants first rated their desired health, considered a landmark and then rated their current health (Peetz \& Wilson, 2012, Study 3-5). 
Aside from highlighting the gap between the current and a desired state, temporal landmarks can also inspire behavior change as they demarcate the beginning of a new time category, a "fresh start" (Dai, Milkman, \& Riis, 2014; 2015). Dai et al. (2014) showed that the beginning of a new temporal period increases aspirational and goal-oriented behaviours. For instance, people search for the word "diet" using online search engines more often following temporal landmarks (e.g., start of new calendar week, month, year, as well as following federal holidays), and participants made more commitment promises to themselves following the beginning of a new week, month, year, and after holidays.

Second, however, temporal landmarks that place the future self in the same category as the present self can also motivate goal-directed activities. Categorizing a goal in the same temporal category as the present can facilitate an implemental mindset and increase the likelihood that a task is initiated. Tu and Soman (2014) showed that students who thought about a task with a deadline just before the first day of the next month (i.e., just before a landmark) started working on the task earlier than when the deadline was in the "next" temporal category (i.e., just a day later on the first day of the next month). Similarly, farmers with the goal to save a given amount of money were more likely to open a savings account immediately if the saving deadline was framed as just before the new year (i.e., before the New Year's Day landmark) than when the deadline was just a day later (Tu \& Soman, 2014).

In sum, temporal landmarks have clear potential to affect goal pursuit: when highlighting the discrepancy with a desired state (Peetz \& Wilson, 2012), when demarcating a "fresh start" (Dai et al., 2014), or when increasing the perceived imminence of a goal deadline (Tu \& Soman, 2014), landmarks might spur people to initiate or maintain goal pursuit. However, the way temporal landmarks affect goal pursuit likely depends on a host of factors (e.g., goal clarity and 
commitment, discrete vs. ongoing goals). More research is needed to distinguish when intervening vs. connecting landmarks motivate - and, more generally, when connection to future selves or contrast with future selves motivates.

Meaning in life. Besides identity and goal pursuit, temporal landmarks may also affect other aspects of our lives. For instance, the transition experience or "fresh start" experience that seems to be created by temporal landmarks can lead people to search for meaning in their life (Alter \& Hershfield, 2014). People tend to ponder the meaningfulness of life more when transitioning to a new decade in life: those faced with turning 30,40 , 50, etc were more likely to subscribe to dating sites, run a marathon for the first time in their lives, and more likely to commit suicide than those with less momentous upcoming birthdays (e.g., 28, 38, 48). Individuals with a milestone birthday judged their level of life satisfaction by reflecting on their life currently and over time, as opposed to individuals with a non-milestone birthday who based their life satisfaction off their daily emotional trends (Miron-Shatz, Bhargave, \& Doniger, 2015). A milestone birthday can therefore not only acts as a temporal landmark, but also promotes an overall examination of one's life.

Future research might determine if the same focus on meaningfulness of life and subsequent behavior changes may be recreated for mundane landmarks that don't inherently include an identity shift. Would people be more likely to turn their life around and ponder the meaning of life in response to highlighting temporal landmarks such as weekends on a calendar or Christmas Day? More generally, one might ask: Are there some temporal landmarks that are more effective in regulating the connection between temporal selves than others?

\section{The type of landmark matters}


So far, existing work has shown that personal events (birthdays, anniversaries), culturally shared events (holidays, famous people's birthdays), and even arbitrary markers of time counting systems (first of the month, start of a week, weekends) stand out on the temporal landscape. Consequently, these landmarks have the potential to shape responses to events on the temporal horizon, shifting identity and affecting goal pursuit. However, although studies on landmark effects have used a wide variety of experimenter-selected or self-nominated temporal landmarks (Alter \& Hershfield, 2014; Cantor et al., 1987; Dai, Milkman, \& Riis, 2014, 2015; Kling, Ryff, \& Essex, 1997; Peetz \& Wilson, 2012; Tu \& Soman, 2014; Uzer \& Brown, 2015; Zwartz \& Sharman, 2013), temporal landmarks may not all be created equal. It stands to reason that some events loom larger than others. A personally meaningful unique event might shape people's responses more than a mundane event with little psychological meaning. In other words, there might be boundaries to just how mundane or meaningless the personal or cultural connection of a temporal landmark can be before it is no longer an effective boundary for temporal categories. Indeed, when highlighting completely meaningless events - Roman holidays participants had never heard of, such as "Portunalia" or "Meditrinalia" - that fell either before or after a future self, these minimal landmarks did not affect the connection between temporal selves (Peetz \& Wilson, 2016).

Logically, the most effective barriers against negative temporal selves and the most effective cues for "fresh starts" facilitating goal pursuit might be those landmarks that have the most personal impact. Indeed, Dai et al. (2015) showed that both the inherent meaningfulness of a landmark (e.g., imagine moving for the first time in nine years vs. imagine moving every year) and framing a landmark as meaningful (e.g., framing March 23 as the "1st day of spring" vs. "3rd Thursday in March") influenced whether the landmark spurred goal pursuit. Furthermore, 
framing a temporal landmark as meaningful, highlighted the gap between selves, thereby affecting people's motivation to pursue goal (Dai et al., 2015). This work also echoes the finding that more meaningful birthdays (transitions to the next decade of life, e.g., turning 30, 40) seem to engender more change and pondering of life than less meaningful birthdays (e.g., turning 29, 39; Alter \& Hershfield, 2014).

It is important to note that while the personal relevance of events clearly is linked to their effect on shaping the temporal landscape and subsequent thoughts and behaviors, even relatively minor events (that maintain at least a minimum of personal meaning) have the potential to serve the same function. Even an event of minimal personal relevance (first day of spring; Dai et al., 2015, birthday of a late president, Peetz \& Wilson, 2012) may acquire the power to shift temporal categories when people are motivated to use them as "fresh start" indicators or as barriers between selves. However, to date this has only been shown for temporal landmarks located in the future - research on the role of temporal landmarks in the past have focused on major life transitions rather than mundane landmarks.

\section{The temporal horizon matters}

An important aspect of the influence of temporal landmarks may be how far the temporal horizon extends into the past or the future. Existing work on temporal landmarks in the past focused on longer time frames - the examined memories dated years back and some work examined participants entire past lives (Skowronski et al., 2007; Thomsen, 2009; Thomsen \& Berntsen, 2008). In contrast, existing work on temporal landmarks in the future mostly focused on smaller time frames - the future selves participants aspired to or feared were usually between 6 weeks and 6 months in the future (Peetz \& Wilson, 2012, 2013; Tu \& Soman, 2014), and as short as one week in the future (Dai et al., 2015; Tu \& Soman, 2014). 
What might be consequences of expanding or collapsing the temporal horizon in which temporal landmarks are placed? Are there boundaries at which point temporal categories cease being plausible or meaningful (e.g., a temporal category spanning the next ten years or the next ten minutes). Future research might examine the interplay between temporal horizons and temporal landmarks. The larger the temporal horizon, the more meaningful a temporal landmark might have to be to separate this temporal landscape into individual categories. Reducing the temporal horizon, may result in very frequent and smaller temporal categories while retaining the benefits of starting a new category. For example, one way to extend positive effects of the "fresh start effect" (Dai et al., 2014) over a longer period of time may be to conceive each day as a fresh start. To this end, a "fresh start calendar" could represent a new day and each page flip symbolizing temporal landmark separating the past self from the present. When comparing such a fresh start calendar to a regular weekly calendar in their plans for a health-related goal (walking 50,000 steps a week), those participants who used the "daily" planner intended to take more steps than those who used the "weekly" planner (Davydenko, 2016). Future research may determine how temporal landmarks or temporal categories can foster aspirational behaviour for longer periods - and the minimum time required to form meaningful temporal categories or induce a feeling of the future self being "different".

On the other hand, there might also be boundaries to how large temporal categories may be to still meaningfully organize identity and behavior. Are temporal categories extending beyond one's own lifetime still meaningful? Such long-term horizons and distant temporal landmarks might shape the collective self (Tajfel \& Turner, 1986; Markus \& Kitayama, 1994) rather than the personal self. For example, highlighting an important collective event (e.g., an election) might change the perception of the group (e.g., one's country) as being similar or 
dissimilar to the group in the past, depending on whether the highlighted event places the present time in the same or in a different temporal category.

\section{Applications}

The role temporal landmarks play in structuring our sense of time and self remains uncharted in many ways and more research is needed to provide a fuller picture of how temporal landmarks may impact affect, cognition, and behavior. For example, research on temporal landmarks in the past has focused on significant landmarks, such as life transitions, and has not yet examined whether mundane landmarks are as effective as creating temporal categories in the past as they are in creating temporal categories in the future. Do mundane landmarks have the same benefits for memory (e.g., Kurbat et al., 1998; Zwartz \& Sharman, 2013) and impact on creating "life chapters" (e.g., Cantor et al., 1987) as more significant landmarks? Additionally, landmarks in the past further deserve attention since they could play a role in people coming to terms with negative past experiences, by placing them in a separate temporal category. In such a context, temporal landmarks may have therapeutic potential, as they can provide psychological barriers that may help protect people's identity and self-esteem.

Specifically, people might use temporal landmarks to manage the psychological connection to past events. Just as negative past events tend to feel more subjectively distant than positive events that occurred at the objectively same time (see Wilson \& Williams, this handbook), more intervening events might come to mind when reflecting on the time passed since a negative event. Thus, just as participants selectively chose to focus on landmarks that managed the connections between their current self and a future self (Peetz \& Wilson, 2013), people may use landmarks to regulate the connection to past selves. This spontaneous landmark use may take the form of intrapersonal reflections (e.g., by bringing to mind a past landmark to 
increase separation from an even earlier negative event) and interpersonal efforts (e.g., by discussing with others intervening events that separate the self from undesirable events).

Indeed, in some cases, people might even "create" these landmarks - having gotten a makeover might create disconnection between now and a painful relationship break-up and planning a party might crease disconnection between now and a dreaded upcoming surgery. Future research should examine more closely how landmarks are spontaneously used in regulating affect (e.g., self-appraisal, self-esteem), cognition (e.g., identity, goal setting) and behavior (e.g., goal pursuit). It is possible that people prefer to reflect on - or even instigate - a slightly negative event simply for the purpose to place a psychological barrier between the present and a more negative experience further in the future. Similarly, people might keep the memory of a slightly negative event alive because it helps them to psychologically separate from a very negative experience that occurred earlier.

One way in which temporal landmarks may be used in real life (i.e., outside the lab) is via calendars. Calendars are ubiquitous in our lives and the type of events we choose to enter (highlighting Christmas day or marking birthdays with stars) and the format of the calendar we choose (daily, monthly, yearly) might serve to highlight or obscure temporal landmarks. Indeed, the formatting of calendars has been shown to affect people's cognitions. Formatting changes as simple as shading different parts of a background and separating temporal units created psychological temporal categories (Study 4 and 5 in Tu \& Soman; Study 5 in Peetz \& Wilson, 2012). Calendars might be a commonplace and ubiquitous way to manage temporal landscapes and organize one's life into temporal categories.

\section{Conclusions}


The way we represent time is meaningful and has many consequences - highlighting specific dates can affect how we see ourselves now and in the future, and can affect the motivation to achieve goals. Yet, we almost never think about the format in which time is represented or which temporal landmarks stand out on our mental temporal landscape. Any day, someone might mention a temporal landmark in conversation, reminders for an event may be encountered (e.g., a save-the-date card on the fridge), or a calendar might section time in a particular way (months, weeks) - all these aspects of time representation can influence how we think about our future and past selves, and influence whether we pursue our goals. More research is needed to shed light on the ways in which these everyday time markers influence time representation and downstream cognition. 


\section{References}

Adriaanse, M. A., de Ridder, Denise T. D., \& de Wit, John B. F. (2009). Finding the critical cue: Implementation intentions to change one's diet work best when tailored to personally relevant reasons for unhealthy eating. Personality and Social Psychology Bulletin, 35(1), $60-71$.

Alter, A. L., \& Hershfield, H. E. (2014). People search for meaning when they approach a new decade in chronological age. PNAS Proceedings of the National Academy of Sciences of the United States of America, 111(48), 17066-17070.

Amir, O., \& Ariely, D. (2008). Resting on laurels: The effects of discrete progress markers as subgoals on task performance and preferences. Journal of Experimental Psychology: Learning, Memory, and Cognition, 34(5), 1158-1171.

Bartels, D. M., \& Rips, L. J. (2010). Psychological connectedness and intertemporal choice. Journal of Experimental Psychology: General, 139(1), 49-69.

Brown, N. R., Shevell, S. K., \& Rips, L. J. (1986). Public memories and their personal context. Autobiographical memory. (pp. 137-158) Cambridge University Press, New York, NY.

Cantor, N., Norem, J. K., Niedenthal, P. M., Langston, C. A., \& Brower, A. M. (1987). Life tasks, self-concept ideals, and cognitive strategies in a life transition. Journal of Personality and Social Psychology, 53(6), 1178-1191.

Carver, C.S., \& Scheier, M. F. (1998). On the self-regulation of behavior. New York: Cambridge University Press.

Dai, H., Milkman, K. L., \& Riis, J. (2014). The fresh start effect: Temporal landmarks motivate aspirational behavior. Management Science, 60(10), 2563-2582. 
Dai, H., Milkman, K. L., \& Riis, J. (2015). Put your imperfections behind you: Temporal landmarks spur goal initiation when they signal new beginnings. Psychological Science, 26(12), 1927.

Davydenko, M. (2016). Making every day a fresh start. Unpublished manuscript. Carleton University.

Ersner-Hershfield, H., Wimmer, G. E., \& Knutson, B. (2009). Saving for the future self: Neural measures of future self-continuity predict temporal discounting. Social Cognitive and Affective Neuroscience, 4(1), 85-92.

Hoyle, R. H., \& Sherrill, M. R. (2006). Future orientation in the self-system: Possible selves, self-regulation, and behavior. Journal of Personality, 74(6), 1673-1696.

Kling, K. C., Ryff, C. D., \& Essex, M. J. (1997). Adaptive changes in the self-concept during a life transition. Personality and Social Psychology Bulletin, 23(9), 981-990.

Koo, M., \& Fishbach, A. (2008). Dynamics of self-regulation: How (un)accomplished goal actions affect motivation. Journal of Personality and Social Psychology, 94(2), 183-195.

Kurbat, M. A., Shevell, S. K., \& Rips, L. J. (1998). A year's memories: The calendar effect in autobiographical recall. Memory and Cognition, 26(3), 532-552.

Larsen, S. F., Thompson, C. P., \& Hansen, T. (1996). Time in autobiographical memory. Remembering our past: Studies in autobiographical memory. (pp. 129-156) Cambridge University Press, New York, NY.

Loftus, E. F., \& Marburger, W. (1983). Since the eruption of Mt St Helens, has anyone beaten you up? Improving the accuracy of retrospective reports with landmark events. Memory and Cognition, 11(2), 114-120. 
Markus, H. R., \& Kitayama, S. (1994). A collective fear of the collective: Implications for selves and theories of selves. Personality and Social Psychology Bulletin, 20(5), 568-579.

Miron-Shatz, T., Bhargave, R., \& Doniger, G. M. (2015). Milestone age affects the role of health and emotions in life satisfaction: A preliminary inquiry. PLoS ONE, 10(8).

Oettingen, G., \& Gollwitzer, P. M. (2009). Embodied goal pursuit. European Journal of Social Psychology, 39(7), 1210-1213.

Oettingen, G., Mayer, D., Sevincer, A. T., Stephens, E. J., Pak, H., \& Hagenah, M. (2009). Mental contrasting and goal commitment: The mediating role of energization. Personality and Social Psychology Bulletin, 35(5), 608-622.

Oettingen, G., Mayer, D., \& Thorpe, J. (2010). Self-regulation of commitment to reduce cigarette consumption: Mental contrasting of future with reality. Psychology and Health, 25(8), 961-977.

Parfit, D. (1971). Personal identity. Philosophical Review, 80(1), 3-27.

Parfit, D. (1984). Reasons and persons. Oxford: Clarendon Press.

Peetz, J., Wilson, A. E., \& Strahan, E. J. (2009). So far away: The role of subjective temporal distance to future goals in motivation and behavior. Social Cognition, 27(4), 475-495.

Peetz, J., \& Wilson, A. E. (2012). The post-birthday world: Consequences of temporal landmarks for temporal self-appraisal and motivation. Journal of Personality and Social Psychology, 104(2), 249-266.

Peetz, J., \& Wilson, A. E. (2013). Marking time: Selective use of temporal landmarks as barriers between current and future selves. Personality and Social Psychology Bulletin, 40(1), 4456. 
Peetz, J., \& Wilson, A. E. (2013). I'm still on this side of summer break: How managing the connection to a future self can protect current well-being. Paper presented at the annual convention of the Canadian Psychological Association, Ottawa, ON.

Peetz, J. \& Wilson, A. E. (2016). Pushing the boundaries: Roman holidays as temporal landmarks. Unpublished manuscript. Carleton University.

Pillemer, D. B., Rhinehart, E. D., \& White, S. H. (1986). Memories of life transitions: The first year in college. Human Learning: Journal of Practical Research \& Applications, 5(2), 109-123.

Robinson, J. A. (1986). Temporal reference systems and autobiographical memory. In D. C. Rubin (Ed.), Autobiographical Memory (pp. 159-188). Cambridge: Cambridge University Press.

Ross, M., \& Wilson, A. E. (2002). It feels like yesterday: Self-esteem, valence of personal past experiences, and judgments of subjective distance. Journal of Personality and Social Psychology, 82(5), 792-803.

Rubin, D. C., Wetzler, S. E., \& Nebes, R. D. (1985). Autobiographical memory across the lifespan. Autobiographical Memory. Cambridge: Cambridge University Press.

Shum, M. S. (1998). The role of temporal landmarks in autobiographical memory processes. Psychological Bulletin, 124(3), 423-443.

Skowronski, J. J., Ritchie, T. D., Walker, W. R., Betz, A. L., Sedikides, C., Bethencourt, L. A., \& Martin, A. L. (2007). Ordering our world: The quest for traces of temporal organization in autobiographical memory. Journal of Experimental Social Psychology, 43(5), 850-856. 
Tajfel, H., \& Turner, J. C. (1986). The social identity theory of intergroup behavior. In S. Worchel \& W. G. Austin (Eds.), Psychology of Intergroup Relations (2nd ed., pp. 7-24). Chicago: Nelson-Hall.

Thompson, C.P., Skowronski, J.J., Larsen, S., \& Betz, A.L. (1996). Autobiographical memory: Remembering what and remembering when. Hillsdale, NJ: Lawrence Erlbaum Associates Inc.

Thomsen, D. K., \& Berntsen, D. (2008). The cultural life script and life story chapters contribute to the reminiscence bump. Memory, 16(4), 420-435.

Thomsen, D. K. (2009). There is more to life stories than memories. Memory, 17(4), 445-457.

Tu, Y., \& Soman, D. (2014). The categorization of time and its impact on task initiation. Journal of Consumer Research, 41(3), 810-822.

Ungemach, C., Stewart, N., \& Reimers, S. (2011). How incidental values from the environment affect decisions about money, risk, and delay. Psychological Science, 22(2), 253-260.

Uzer, T., \& Brown, N. R. (2015). Disruptive individual experiences create lifetime periods: A study of autobiographical memory in persons with spinal cord injury. Applied Cognitive Psychology, 29(5), 768-774.

Wilson, A. E., \& Ross, M. (2000). The frequency of temporal-self and social comparisons in people's personal appraisals. Journal of Personality and Social Psychology, 78(5), 928942.

Wilson, A. E., \& Ross, M. (2001). From chump to champ: People's appraisals of their earlier and present selves. Journal of Personality and Social Psychology, 80(4), 572-584. 
Zwartz, M., \& Sharman, S. J. (2013). Using personal landmark events improves judgments about time, but not contents, in autobiographical memory. Applied Cognitive Psychology, 27(3), 286-290. 